\title{
THE MEMORY OF PLACES \\ THE SURVEY, REINVENTION AND RECONSTRUCTION OF A SMALL AGRICULTURAL ARTEFACT IN THE MOUNTAIN VILLAGE OF QUOTA, CASENTINO, ITALY
}

\author{
G. Pancani ${ }^{1, *}$, A. Ricci $^{1}$ \\ ${ }^{1}$ Dept. of Architecture, DiDA, University of Florence, Italy - (giovanni.pancani, andrea.ricci)@ unifi.it
}

Commission II - WG II/8

KEY WORDS: Survey, Recovery, Reinvention, Mountain villages

\begin{abstract}
:
The "history" of places exists as a stratification process of events that have occurred over time in a specific place, leavin g more or less appreciable physical traces. The "memory" of the places, instead, is the result of a conscious choice of events to be handed down to future generations constructing the identity of a community and a recognisable image of places. It is in this sense that the project conducted in Quota, a mountain village in central Tuscany, Italy should be interpreted and set. The urban redevelopment process led to the design and reconstruction of a small agricultural artefact, particularly important to the local community given its location near a public fountain. Initially identified as the subject of an exercise to be conducted as part of the Thematic Seminar "Survey, redevelopment and redesign of architecture and environment", the redesign offered an opportunity to "reinvent" a neglected corner of the village taking as reference the traces of the ancient village fountains to create the plot of a new "story" involving the small local community. The reconstruction was carried out using traditional techniques with stone ashlars and cement mortar. To complete it, a corten steel staircase designed with reverse engineering methods and modelled using experimental 3D photo-modelling was created. The "Quota chestnut dryer" proved to be a virtuous process involving various subjects to enable the recovery of a degraded area, a possible model for the preservation of villages in the Apennines of cen tral Italy, authentic sites of collective memory.
\end{abstract}

\section{INTRODUCTION}

The "history" of places exists as an accumulation of all the events which happened there: the temporal succession of endless additions and subtractions creating its current state. The "memory" of places, on the other hand, implies a selection of the events. It derives from the creation of an awareness, more or less widely agreed and acknowledged, of the continuity and/or greater importance of specific, unifying moments within the historical succession (Pandolfi, 2019).

In this sense, it can be considered as more of a "creation" not so much of the individual but as the progressive evolution of a path towards an identity decided by a group or a community. Memories are created as a result of the ability of certain events to leave their mark on a place and are consolidated by the persistence of the historical, social, economic and ideological conditions that led to their very creation. In the same way they can cease to exist, sometimes in the space of one or two generations (Rossi, 1996).

The work carried out in the Village of Quota, on the slopes of the Casentino side of Pratomagno between Florence and Arezzo, a joint project of the University, the local administration and the village community, aimed to reawaken this "memory" of place through a number of small restoration and redevelopment initiatives (Pazzaglini, 2019).

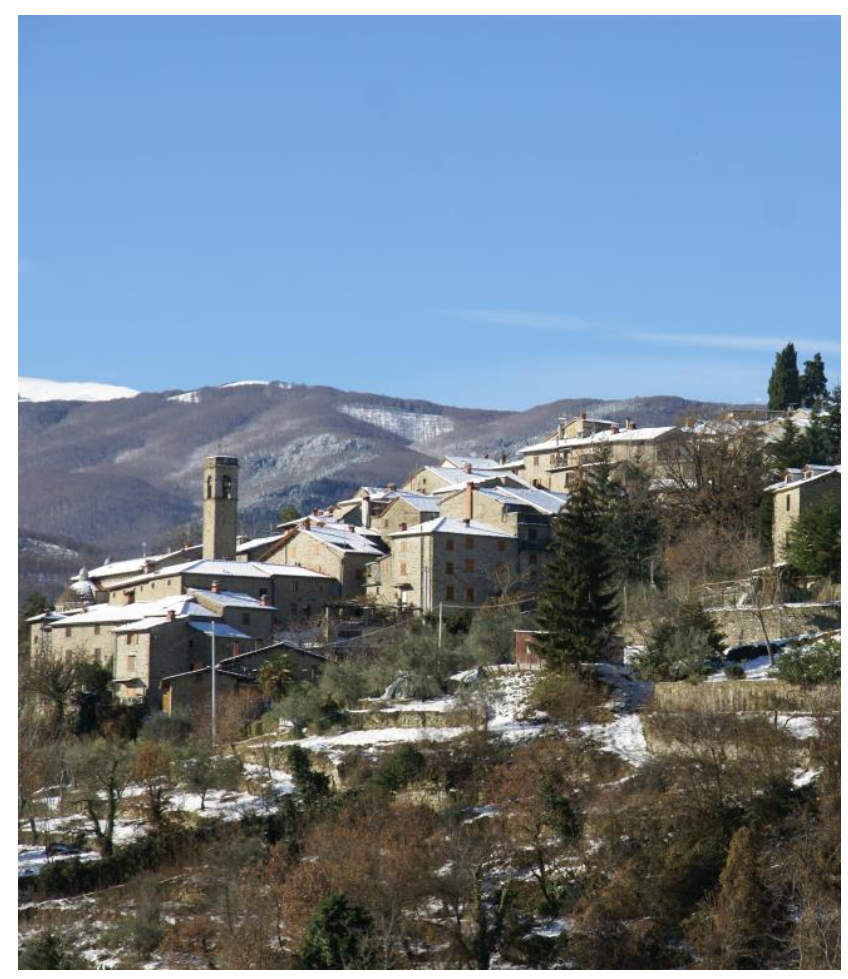

Figure 1. The village of Quota on the slopes of Pratomagno on the side of the Casentino valley.

\footnotetext{
* Corresponding author
} 


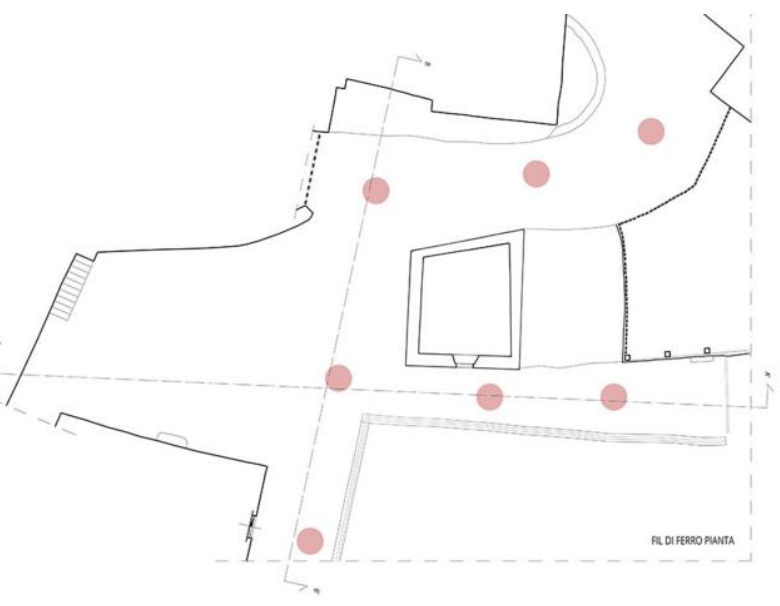

Figure 2. Planimetric survey of the project intervention area.

\section{PROJECT AND PLACE}

The Casentino village of Quota does not vaunt striking elements of historical-artistic interest. The physical evidence of its history is limited and unable to generate an image recognizable to those without specific disciplinary skills. More than by the presence of identifiable objects, here the memory of the place lies in the way the area has been organised to optimize the possibilities of use; from the structure of the local settlement that evolved from the Middle Ages to the present day, to the complex grid of connections linking important sites. Restoring this memory means acknowledging that while the crisis brought about by the current transformation of the local community's needs cannot be ignored in the name of preserving past tradition, nor can it become the pretext for importing pre-packaged growth models that are out of context.

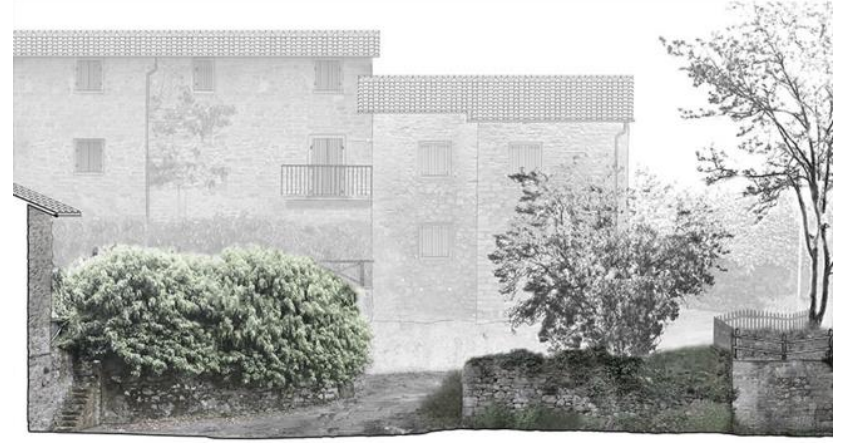

Figure 3. Survey, elevation on the road of the source before the restoration of the area.

Given the progressive, technical adaptation of the local village to the normal needs of contemporary life, new elements therefore need to be found within the same general design; elements able to blend in with the pre-existing, in the same manner as the buildings of the present town of Quota have their foundations in the structures of the ancient settlement. Only a few "original" stones surface from the more recent masonry, but the memory of the ancient building still exists in those houses, precisely as a result of a design dimension that has always been in line, and not in contrast, with the past. Within the scope of the teaching activities of the Thematic Seminar "Survey, redevelopment and redesign of architecture and environment", it would have been at the very least anachronistic to develop a project proposing a mere relocation to the original sites of the many fountains that characterized the town and the immediate surroundings of Quota (today largely out of use or vanished). Long ago, these fountains ensured the supply of water, but were also natural meeting places for the community, recognisable reference points, constituting a sort of local "map". The attempt to restore those places for similar purposes today would at most constitute a questionable attraction for tourists. The objective of any project should not be to physically reconstruct what was lost (extending the concept of "where it was, as it was" is somewhat risky aside from specific circumstances), but rather to re-invent the memory of places within new elements of meaning. The question of the fountains of Quota, proposed by the Thematic Seminar as a project, is an opportunity to use the traces of almost forgotten places in the plot of a new story developing in the territory. In the passages of this plot the traditional characters are confronted with new situations that force them to change their role and image.

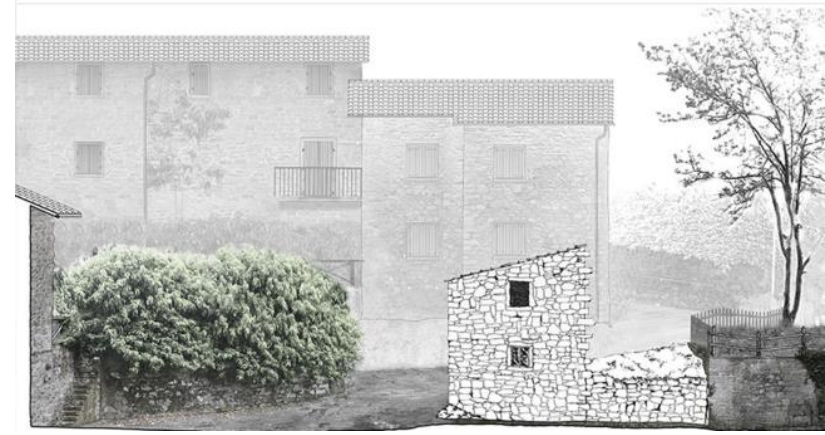

Figure 3A. Survey elevation on the road of the source with the design of the small building (Dryer) made when it was still intact, 1986 around.

The fountains involved in the project are not mere artefacts used to supply and/or contain the celebrated waters of Quota, but are the formal and symbolic means for making the places recognisable. In a natural context, outside the residential area, the "king's" fountain can be interpreted as a sign, inviting discovery of the place hidden under street level from where the water flows. In the square with the only vehicle access, the "bridge" fountain appears as the first garrison of the village, just below the imposing rock wall which the oldest part of the town perches on. Inside the residential area, the memory of an old chestnut "dryer", leaning against the slope at a bend in the road, provides the theme of the project; a virtual "inner space" concealing and guarding the water reservoir.

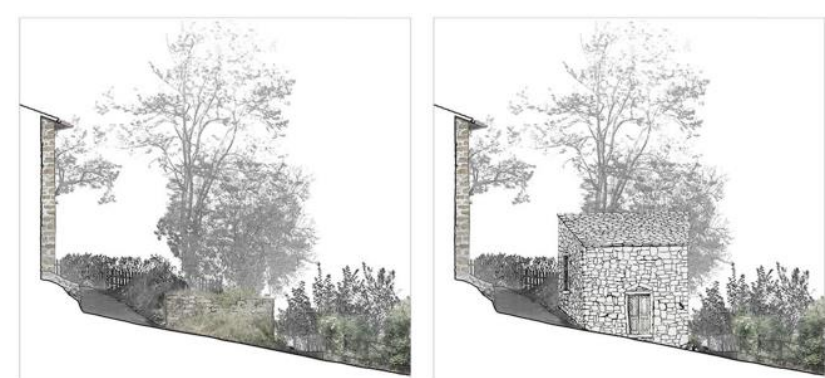

Figure 4. Survey elevation on the road, of the source before the restoration of the area, and $3 \mathrm{~A}$. with the design of the small building (Dryer) made when it was still intact, 1986 around. 
The enclosure does not reproduce the planimetric characteristics of the dryer, nor does the position of the original fountain coincide with the present one, yet the project conserves the memory of the place.

This duality of relationship between continuity and innovation, between tradition and new needs is the theoretical basis of any architectural debate on the theme of memory and a factual element of the formal choices made regarding the architectural material of the building. The external masonry enclosure uses the same stone as the village walls, as if it were part of the same. The "modern feature", consisting of the stairway belvedere in corten occupies the entire interior, covers and protects the fountain. A thin layer of water lies between the naturalness of the rocky outcrop and the absolute artificiality of the metal roof. The two realities, both similar and opposing,

graft into each other in a close contiguity which does not intend to nor could blend. Only in the moving reflection of the liquid surface does the duality compose a fragile oneness which in no case detracts from the recognizability of the parts.

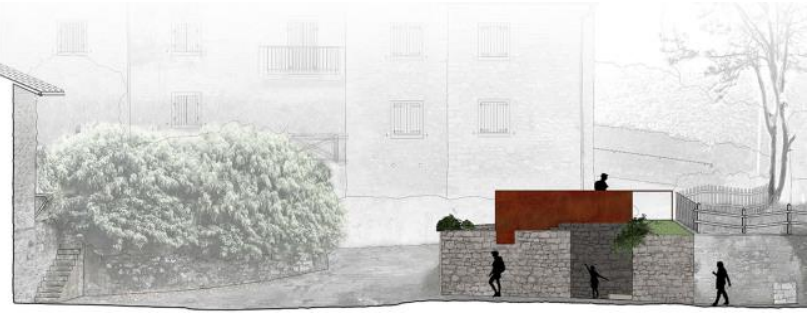

Figure 5. Elevation of the project created by the seminar students.

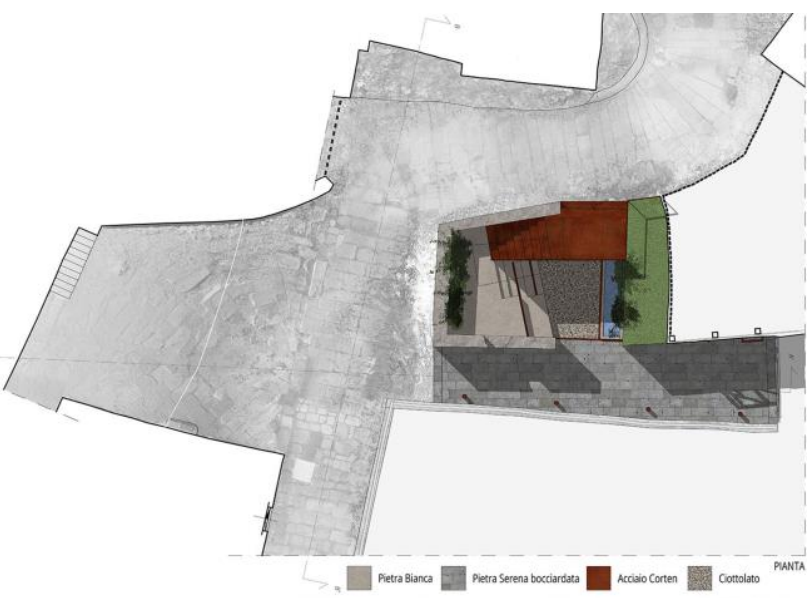

Figure 6. Plan of the project created by the seminar students.

\section{PROJECT AND CONSERVATION}

As said above, the physical consistency of the "dryer" and the old fountain, deteriorated by time and neglect were not considered in the project. There is not a single fragment of the work which might be called "original" as in pertaining to the pre-existing structure, nor is there any reference to traditional local construction methods. In strictly technical terms, the project is an entirely new construction giving a new, formal connotation (legitimate or not) to the site of the "dryer".

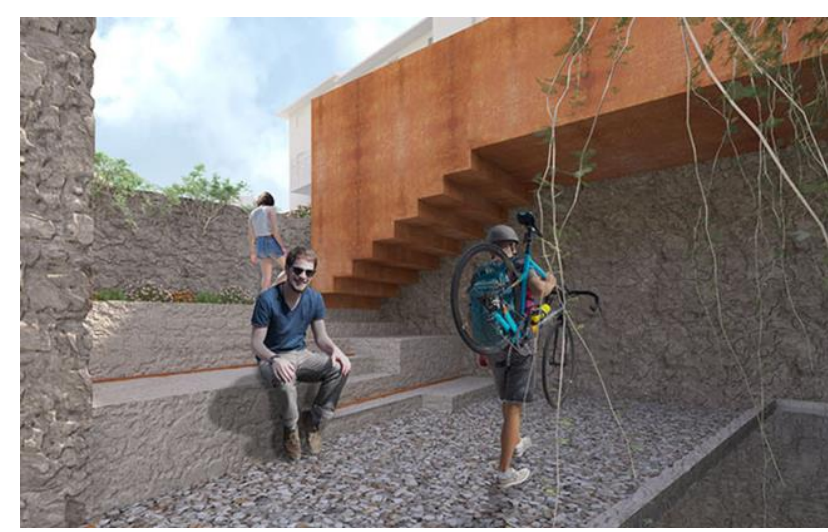

Figure 7. Render of the project.

The project falls entirely within the category of urban redevelopment in its perspective of enhancing and allowing public enjoyment of an area, the original purpose of which was long since abandoned and in a state of neglect.

Within the broader spectrum of the significance of the project however, the concept of "restoration" also applies inasmuch as the project preserves a "figurative" link with everything that has characterised the historic site as a whole, over time. Real conservation does not mean preserving the formal features of things against the passage of time but lies in the continuity of the "figures" which took such forms in the past and maintain such role today.

Restoring memory, through projects similar to that of Quota, is itself a form of restoration; attempting to recreate that sense of belonging to the local community and its history of a specific site rather than merely mimicking the forms/techniques of the past.

\section{PROJECT AND REALISATION}

For once, the unusual combination of university research and local institutions has succeeded in bringing this project to its natural conclusion, namely the construction of the work. This since almost all projects generally remain on paper, especially those developed in the context of university activity. Undoubtedly, favourable and fortunate circumstances determined the positive outcome in this case, but the event invites a brief reflection on the methods and levels of elaboration of the architectural project within a university education. Without wishing to generalize, projects are often seen that, on the one hand propose interesting formal solutions but on the other reveal a manifest difficulty or, worse, a lack of interest, in going beyond the surface of things, in other words beyond the mere image of space. In short, the development of the project in an "evocative" rather than "representative" spatial dimension is preferred. The result of all this is projects that are more suitable for printed paper than for the construction site. The project related to the "dryer" fountain was never brought to the implementation level (it would not have been possible considering the timing of the Thematic Seminar and the objectives of a teaching exercise), but its elaboration was carried out from the very outset on the basis of the constructive plausibility of the choices made. This is why the small, almost inevitable changes and adaptations made in the executive and construction phases have not distorted the idea, nor betrayed the initial intentions. If all projects were drawn up (regardless of the sphere of reference) aiming beyond the mere printed document, we might indeed "run the risk" of actually building some further works. 

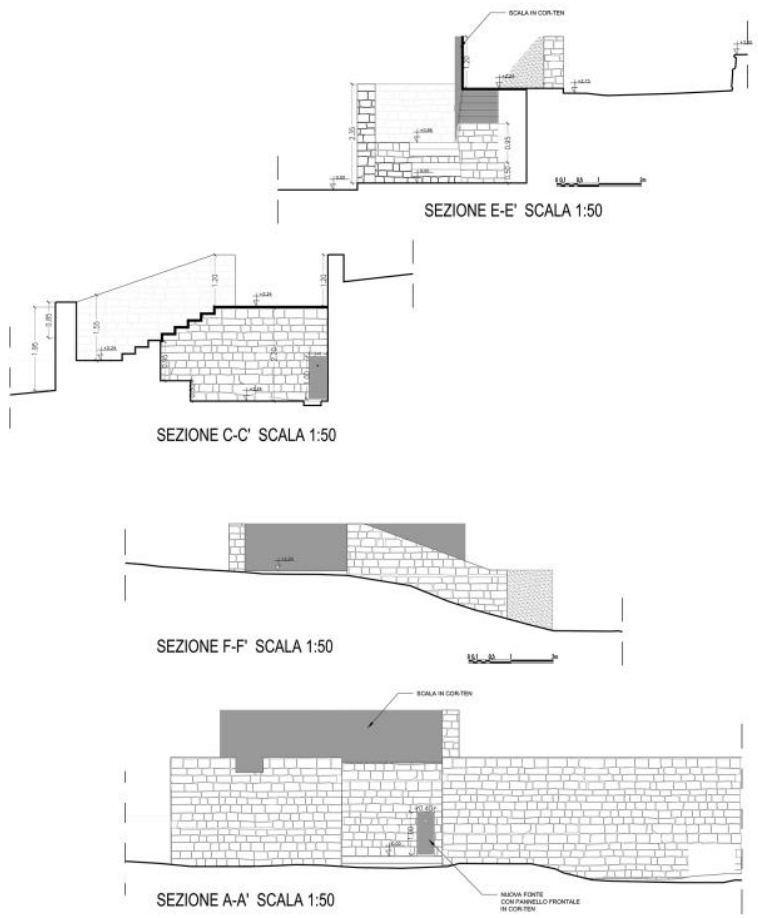

Figure 8. construction project of the small building.

\section{PROJECT DOCUMENTATION AND SITE-UP}

The thematic seminar already included a first survey and documentation phase of the condition of the sites. This first phase was addressed using laser scanner and 3D photomodelling technologies (Gaiani, M., 2015), to document the state of decay of the ruins on the site. At the same time, in order to adequately document the type of artefact existing, direct surveys of the small dryer built in the 1880s, when the small building was still in good condition, were juxtaposed. For the transformation process from the project to site set-up for the realisation of the artefact, the survey previously conducted was needed. The laser scanner survey carried out during the study phases for the redevelopment of the area was enriched during the reconstruction phase with orthophotos produced using 3D photomodelling techniques, in the representations of the elevations, the drawings made following the 1986 survey were added. This method of representation made it possible to assess the change and degradation of the area over the last 30 years and also to verify the typological and metric-morphological characteristics of the dryer before it was partially demolished.

Dryer..Two-storey stone buildings ..., roofs covered with stone slabs, located near the chestnut grove. The two floors are separated by a grate which the chestnuts are arranged on, ...which, once unloaded, are distributed to form an even layer of about $70 \mathrm{~cm}$, situated at a height of two metres from the fire........... The fire remains lit continuously for 20-40 days until the fruit is completely dry (Giovannelli C. 2008).

The building marked the crossroads where the small path leading to the so-called "Lastro" fountain, about 15 metres long, branched off from the main village.

The site set-up for the project involved some small changes to adapt the work carried out by the students in the thematic seminar to current regulations, but also some design simplifications to adapt it to the modest budget that, with a significant economic effort, had been made available by the administration of the small town of Poppi. The type of masonry envisaged by the project, in stone with irregular ashlars, but with rows as recurrent as possible, is typical of the area. This technique, effectively implemented by local workers, was used for all the retaining walls for which the resistance to stresses under and over ground was calculated using rigid block and elevation models (Galassi et al. 2018a,b; 2019), of the small artefact. As regards the inner staircase in COR-TEN steel (weathering steel) this was made in a single monobloc, the executive design of which used reverse engineering techniques "Reverse engineering is the process of duplicating an item, functionally and dimensionally, by physically examining and measuring existing parts to develop the technical data (physical and material characteristics) required for competitive procurement "(Department of Defense, 2006).

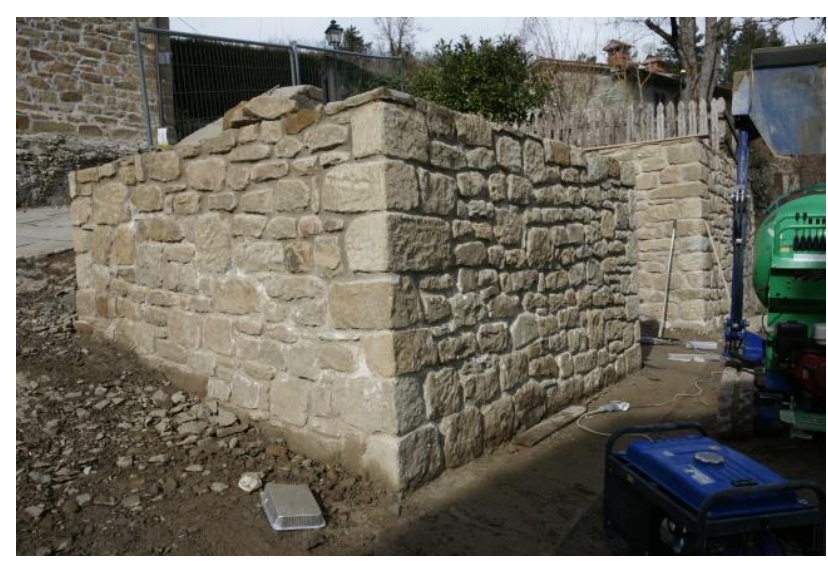

Figure 9. The new building under construction.

\section{MODELLING}

The realization of the COR-TEN steel staircase in a single monobloc was necessary to contain costs. In fact, thanks to the system of installation and fixing of the staircase and masonry, the assembly work was carried out in a single morning. However, in part due to the morphology of the project, the staircase had many angles other than right angles, so that it was not easy to carry out a correct reconstruction, above all because on site assembly had not been envisaged and therefore it was not possible to make any adjustments and corrections during the installation. Given the above, it was therefore necessary to envisage a precise survey of the artefact once the masonry work was completed, and on that survey to carry out the executive project of the staircase in corten. The survey could have been tackled with laser scanner techniques, however, partly because of the difficulty of finding the necessary instrumentation and partly because of wanting to experiment with new techniques, it was decided to address the question by performing a survey with 3D photomodelling techniques SfM, which was completed with some direct measurements, both for the scale and for the control of the final model of the masonry part of the small artefact. In order to comply with the delivery deadlines, the survey was carried out after the completion of the construction of the stone walls, but before the cornice was built and the paving was completed, with the site tools still present on site. These circumstances created a few small problems: once the cornice was put in place, it protruded more than expected, while the site instrumentation made the modelling slightly more complex on account of the awkwardness of some elements present. 
The photographic survey was taken with a Sony Alpha 900 camera, with a $24 \times 36 \mathrm{~mm}$ Full-Frame sensor and resolution of 24 megapixels producing images of $6048 \times 4032$ pixels; the shots were taken with the Sony SAL 24-70mm f/2.8 SSM Zeiss Vario Sonnar $\mathrm{T}^{*}$ zoom lens. The images were processed using the 3DF Zephyr®software, which produced a complete and very detailed model, the model was scaled using eight control points that described 4 half-lines already measured on the part, the half-lines were identified on profiles easily identifiable and arranged according to the three main axes of the artefact (Pancani G., Bigongiari M. 2019).

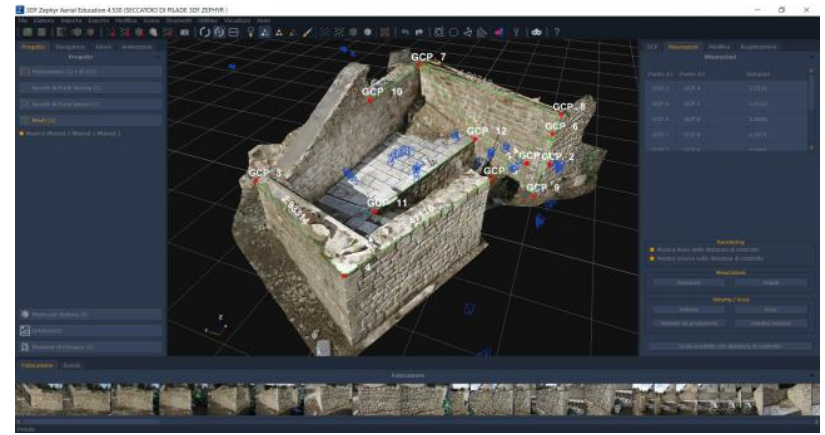

Figure 10. The model of the relief of the new building processed with the 3DF Zephyr®.

The other measurements made were used to check the model. The model was exported to the Recap ${ }^{\circledR}$ program and from there imported into Autocad $₫$ for the realization of the $3 \mathrm{D}$ model of the staircase. In fact, the company that made the Corten hardware works, Laife di Poppi (AR), which is a small but brilliant company present in the Casentino area, carries out metal carpentry work exclusively with numerical control machines, which is why it was necessary to provide them with a 3D model of the part to be made.

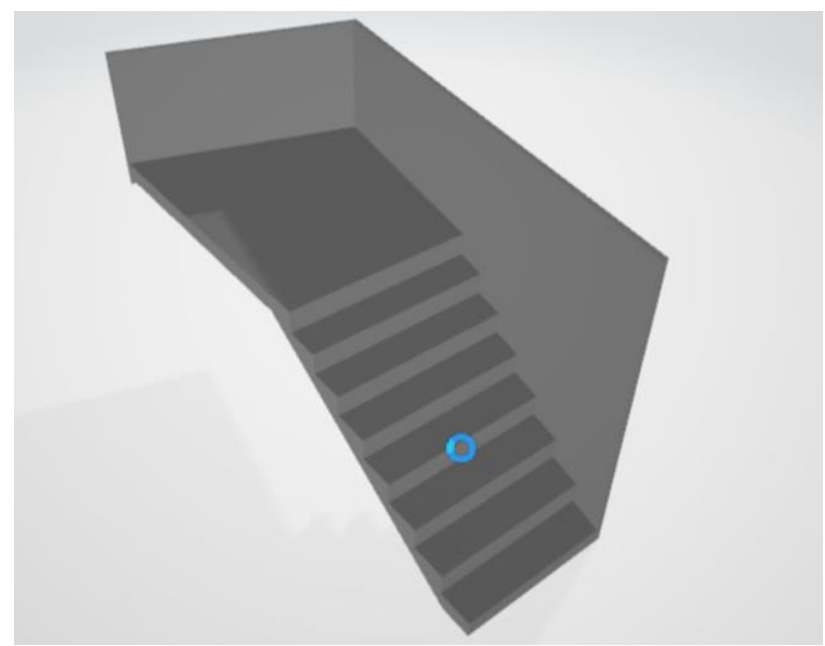

Figure 11. The model performed for the construction of the COR-TEN staircase.

The staircase, built in a single monobloc weighing $1300 \mathrm{~kg}$, was delivered and transported from the unloading yard to the its installation site with a digger. The only final touches required were to the cornice in the portion in contact with the staircase, and at the floor at the support point, in both cases there were two points that had not yet been completed when the survey for the model was made.

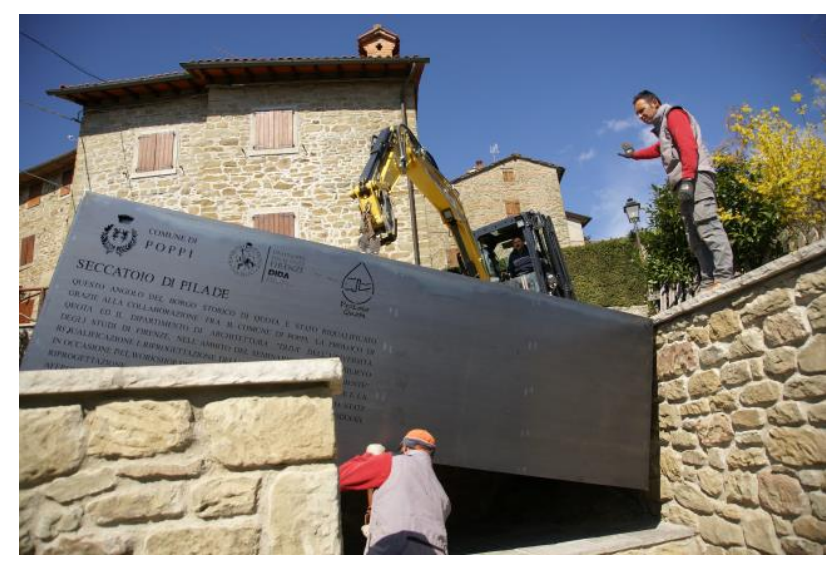

Figure 12. The monobloc of the COR-TEN ladder during the installation operations.

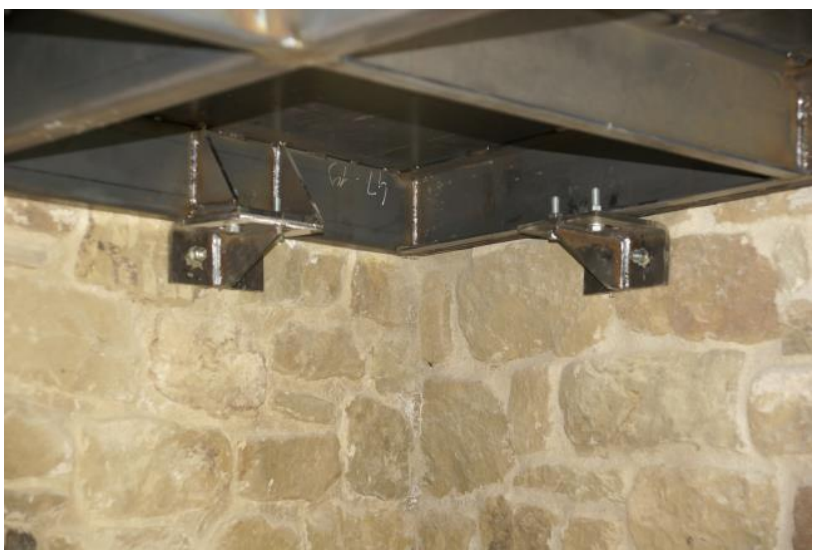

Figure 13. The ladder fixing systemof the COR-TEN staircase.

\section{CONCLUSIONS}

The urban redevelopment and enhancement of a portion of the historic centre of Quota, in some aspects truly unique, benefited from very special circumstances. The project began, in fact, in the context of an academic experience set in this now largely depopulated village, which except for the summer season is reduced to a few dozen inhabitants. Starting from the survey, we conducted all the procedures needed to carry out the project. Thanks to the contribution of the Poppi municipal administration and the local Pro Loco, who believed in the project carried out by the students and decided to finance it, a final executive project was drawn up. The reconstruction of the building, which was carried out using traditional masonry techniques with the use of stone ashlars and cement mortar, was implemented with new materials such as the corten steel staircase, the executive design of which was conducted using reverse engineering techniques, while the material was cut using numerically controlled laser instruments.

This experience thus proved an excellent testing ground for various types of expertise, allowing the experimentation and verification of complex processes. Procedures that enabled the recovery of a degraded area, in a virtuous circle which can be taken as a model for the preservation of the Apennine villages in central Italy, genuine places of collective memory as well as crucial safeguards to counter the advance of environmental degradation, the inevitable consequence of the depopulation of mountain villages. 


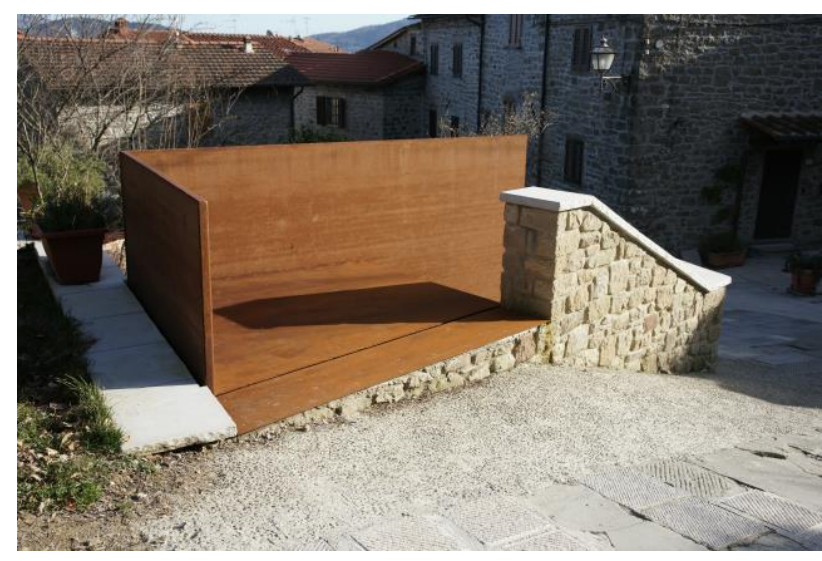

Figure 14. The finished little artifact.

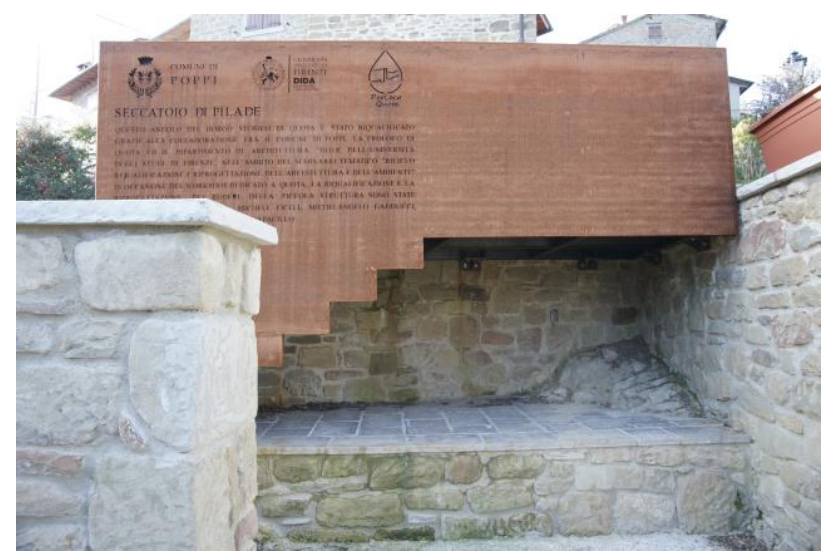

Figure 15. The finished small artifact saw other angle.

\section{ACKNOWLEDGEMENTS}

This research was carried out in the "Survey redevelopment and redesign of architecture and environment" by the teachers: Stefano Bertocci, Giovanni Minutoli, Giovanni Pancani, Paola Puma and Andrea Ricci.

The redevelopment of the area was possible thanks to the collaboration between the Department of Architecture of the University of Florence DiDA, the Municipality of Poppi and the Proloco of Quota. The students Michele Ficeli, Michelangelo Gadducci, Marta Gentili and Gerardo Arcangelo Pacillo participated in the research.

\section{REFERENCES}

Department of Defense, Handbook US Army, Reverse engineering handbook (guidelines and procedures), MILHDBK-115A(ARMY), 1 june 2006 - superseding MIL-HDBK115(ME) 20 april 1987, p. 6.

Gaiani, M., 2015. I portici di Bologna Architettura, Modelli 3D e ricerche tecnologiche, Bologna.

Galassi, S., Ruggieri, N., Tempesta, G., 2018a. A novel numerical tool for seismic vulnerability analysis of ruins in archaeological sites. Int. J. Archit. Herit., 14(1), 1-22, doi.org/10.1080/15583058.2018.1492647.
Galassi, S., Ruggieri, N., Tempesta, G., 2018b. Ruins and archaeological artifacts: vulnerabilities analysis for their conservation through the original computer program BrickWORK. Structural Analysis of Historical Constructions, RILEM bookseries 18, Springer International Publishing, pp. 1839-1848. doi.org/10.1007/978-3-319-99441-3_197, Proc. of 11 th International Conference on structural analysis of historical constructions (SAHC2018) (11-13 September 2018, Cusco, Perù).

Galassi, S., Tempesta, G., 2019. Porta san Giorgio in Florence. Rigid block model analysis for the crack pattern interpretation. COMPDYN 2019 - 7th International Conference on Computational Methods in Structural Dynamics and Earthquake Engineering, pp. 651-662, Ottobre 2019, Proc. of Compdyn 2019, 24-26 June 2019, Crete, Greece.

Giovannelli C., 2007-2008. La castagna: dal bosco alla tavola. Tradizione ed innovazione / The chestnut: from wood to tabel. Tradition and innovation. Tesi di Laurea in Scienze e Tecnologie Alimentari, Relatore Lante A., Università degli Studi di Padova, Facoltà di Agraria, Dipartimento di Biotecnologie Agrarie, a.a. 2007-2008, p. 32.

Pancani G., Bigongiari M. 2019. The integrated survey of the Pergmum by Nicola Pisano in the cathedral of Pisa. Digital Cultural Heritage, pp. 373-388, DOI: 10.1007/978-3-03015200-0, eBook ISBN: 978-3-030-15200-0

Pandolfi P., 2019. Quota, Castello dei conti Guidi in Casentino: La storia, le storie della gente, le immagini. Quaderni della Rillina, n. 18, Edizioni Pegaso, Firenze.

Pazzaglini, M., 2019, Verso una nuova didattica per i laboratori di architettura. Bruno Zevi e la didattica dell'architettura, Quodlibet, Sapienza Università di Roma, Roma.

Rossi, A., 1996. L'architettura della città, Marsilio, Vicenza.

Simioni E., Re C., Mudric T., Pommerol A., Thomas N., Cremonese G., 2019. The International Archives of the Photogrammetry, Remote Sensing and Spatial Information Sciences, Volume XLII-3/W1, 2017. 2017 International Symposium on Planetary Remote Sensing and Mapping, 13-16 August 2017, Hong Kong. 